\title{
Short- and long-term outcomes of laparoscopic surgery for colorectal cancer in the elderly aged over 80 years old versus non-elderly: a retrospective cohort study
}

Yoshitake Ueda ${ }^{1}$, Norio Shiraishi ${ }^{1 *}$ (D), Takahide Kawasaki ${ }^{1}$, Tomonori Akagi², Shigeo Ninomiya ${ }^{2}$, Hidefumi Shiroshita², Tsuyoshi Etoh² and Masafumi Inomata ${ }^{2}$

\begin{abstract}
Background: Recently, colorectal cancer has increased in elderly patients worldwide, with laparoscopic colorectal surgery increasing in elderly patients with colorectal cancer. However, whether laparoscopic colorectal surgery is an optimal procedure for colorectal cancer in the elderly remains unclear. This study aimed to verify safety and curability of laparoscopic colorectal surgery in elderly patients $\geq 80$ years old.

Methods: Patients undergoing curative colorectal surgery from 2006 to 2014 were enrolled and classified into the laparoscopic surgery in elderly patients aged $\geq 80$ years (LAC-E) group, open surgery in elderly patients (OC-E) group, and laparoscopic surgery in non-elderly patients (LAC-NE) group. Short- and long-term outcomes were compared between these groups.

Results: The LAC-E, OC-E, and LAC-NE groups comprised 85, 25, and 358 patients, respectively. Intraoperative blood loss and incidence of postoperative complications were significantly lower in the LAC-E versus OC-E group (97 vs. $440 \mathrm{~mL}, p<.01$ and $14 \%$ vs. 32\%, $p<.05$, respectively). Long-term outcomes were not different between these two groups. Operation time was significantly shorter in the LAC-E versus LAC-NE group (249 vs. $288 \mathrm{~min}, p<.01$ ). Intraoperative blood loss and postoperative complications were similar between the groups. Although the 5 -year overall survival rate in the LAC-E group was lower than that in the LAC-NE group ( $64 \% \mathrm{vs.} 80 \%, p<.01$ ), there was no difference in 5-year disease-specific survival between the groups.
\end{abstract}

Conclusion: Laparoscopic colorectal surgery is technically and oncologically safe for colorectal cancer in the elderly as well as the non-elderly and can be an optimal procedure for colorectal cancer in the elderly.

Keywords: Colorectal cancer, Elderly, Laparoscopic surgery, Safety, Curability

\footnotetext{
*Correspondence: norioh@oita-u.ac.jp

'Department of Comprehensive Surgery for Community Medicine, Oita University Faculty of Medicine, Hasama-machi, Oita 879-5593, Japan

Full list of author information is available at the end of the article
}

(c) The Author(s). 2020 Open Access This article is licensed under a Creative Commons Attribution 4.0 International License, which permits use, sharing, adaptation, distribution and reproduction in any medium or format, as long as you give appropriate credit to the original author(s) and the source, provide a link to the Creative Commons licence, and indicate if changes were made. The images or other third party material in this article are included in the article's Creative Commons licence, unless indicated otherwise in a credit line to the material. If material is not included in the article's Creative Commons licence and your intended use is not permitted by statutory regulation or exceeds the permitted use, you will need to obtain permission directly from the copyright holder. To view a copy of this licence, visit http://creativecommons.org/licenses/by/4.0/. The Creative Commons Public Domain Dedication waiver (http://creativecommons.org/publicdomain/zero/1.0/) applies to the data made available in this article, unless otherwise stated in a credit line to the data. 


\section{Background}

The population of elderly persons, and especially those in Japan aged over 80 years, have been dramatically increasing worldwide. Colorectal cancer is the third most commonly occurring cancer in men and the second in women worldwide [1]. In Japan, the incidence of colorectal cancer was ranked as the most common cancer type and the second leading cause of cancerrelated death in 2019 [2]. Thus, aging could be considered as one of the major risk factors for colorectal carcinogenesis [3]. Consequently, the incidence of colorectal cancer in elderly patients has been increasing year by year in Japan, with more than $25 \%$ of colorectal cancer patients now aged 80 years or over [4].

In the treatment of colorectal cancer, laparoscopic surgery has developed rapidly throughout the world due to advantages such as smaller incision, less pain, reduced intraoperative blood loss, faster recovery, and shorter hospitalization compared with open surgery [5-7]. These clinical benefits of laparoscopic surgery for colorectal cancer have been proved by a series of a large sample, multicenter, randomized controlled trials [8-11]. Laparoscopic colorectal surgery has become a standard procedure for treating colorectal cancer worldwide. As a result, the incidence of laparoscopic colorectal surgery in elderly patients has also been increasing in Japan recently [12]. However, the majority of the previous trials of laparoscopic colorectal surgery was conducted on patients younger than 80 years. In addition, most previous studies have reported only the technical safety and short-term outcomes of laparoscopic surgery in comparison with open surgery for elderly patients, but they did not include long-term outcomes. Thus, it is still unclear whether laparoscopic colorectal surgery is an optimal procedure for colorectal cancer in the elderly.

Therefore, we aimed to evaluate the technical and oncological safety of laparoscopic surgery for elderly patients 80 years and older with colorectal cancer by retrospectively comparing their short- and long-term surgical outcomes with those of open surgery for elderly patients and laparoscopic surgery for non-elderly patients aged $<80$ years.

\section{Methods}

\section{Patients}

Between April 2006 and June 2014, 468 patients with colorectal cancer who underwent curative surgery in our department were enrolled in this retrospective study. Patients with synchronous metastases and patients who received palliative and emergent operations were excluded from this study. The patients were divided into three groups. The laparoscopic surgery in elderly patients (LAC-E) group included 85 patients aged $\geq 80$ years who underwent laparoscopic surgery. The open surgery in elderly patients (OC-E) group included 25 patients aged $\geq 80$ years who underwent open surgery. The laparoscopic surgery in non-elderly patients (LAC-NE) group included 358 patients aged $<80$ years who underwent laparoscopic surgery. Patients' demographics, preoperative and operative variables, the clinicopathological findings, and postoperative short- and long-term outcomes for all patients were obtained from the patients' medical records, operation records, and pathology records in our hospital database. The three groups were examined and compared in terms of patient characteristics such as age, sex, American Society of Anesthesiologists physical status (ASA-PS) classification, presence of symptom, previous abdominal surgery, comorbidities, pre- and post-operative chemotherapy, and pathological findings including tumor location, tumor differentiation, tumor size, pTNM stage (Union for International Cancer Control, 7th edition [13]), and short-term outcomes including operative time, blood loss, intraoperative complication, days to solid diet, length of hospital stay, and postoperative complications. Postoperative complications were defined as any condition requiring conservative or surgical treatment occurring within 30 days after operation. Postoperative mortality was defined as death within 30 days of operation. Postoperative complications included anastomotic leakage, bowel obstruction, enterocolitis, intra-abdominal abscess, intra-abdominal bleeding, and pneumonia. Postoperative complications were assessed using the Clavien-Dindo classification (CD) categories [14]. From the pathological records, the depth of invasion was examined at the longest cut section line of the tumor, and lymph node metastasis was examined at the largest cut section of the lymph node. All tissues were examined by expert pathologists. And, long-term outcomes including 5-year overall survival (OS) and 5-year disease-specific survival (DSS) were evaluated.

\section{Statistical analysis}

Quantitative data are given as the median and range. Differences between the three groups were assessed by the chi-square test, Fisher's exact test, or Mann-Whitney $\mathrm{U}$ test as appropriate. Long-term outcomes were compared between each group by log-rank test and are summarized as Kaplan-Meier curves and hazards ratios with 95\% confidence intervals. These analyses were carried out using SPSS ver. 24 (SPSS Inc., Chicago, IL, USA). A $P$-value $<.05$ was considered statistically significant.

\section{Results}

Characteristics of the patients in the three groups are given in Table 1. The average age of the patients in the LAC-E, OC-E, and LAC-NE groups were 84, 84, and 65 years, respectively. There were no differences between LAC-E and OC-E groups in patient characteristics. The 
Table 1 Patient characteristics

\begin{tabular}{|c|c|c|c|c|c|}
\hline Factors & $\begin{array}{l}\text { LAC-E group } \\
(n=85)\end{array}$ & $\begin{array}{l}\text { OC-E group } \\
(n=25)\end{array}$ & $\begin{array}{l}\text { LAC-NE group } \\
(n=358)\end{array}$ & $\begin{array}{l}\text { LAC-E vs OC-E } \\
P \text {-value }\end{array}$ & $\begin{array}{l}\text { LAC-E vs LAC-NE } \\
P \text {-value }\end{array}$ \\
\hline Age (years, mean $\pm S D$ ) & $84 \pm 4$ & $84 \pm 4$ & $65 \pm 11$ & NS & $<.01$ \\
\hline \multicolumn{6}{|l|}{ Gender } \\
\hline M & 42 & 11 & 227 & NS & $<.05$ \\
\hline $\mathrm{F}$ & 43 & 14 & 131 & & \\
\hline \multicolumn{6}{|l|}{ ASA-PS } \\
\hline 1 or 2 & $65(76 \%)$ & $19(76 \%)$ & 341 (95\%) & NS & $<.01$ \\
\hline 3 or more & $20(24 \%)$ & $6(24 \%)$ & $17(5 \%)$ & & \\
\hline Presence of symptom & $61(72 \%)$ & $22(88 \%)$ & $214(60 \%)$ & NS & $<.05$ \\
\hline Previous abdominal surgery & $23(27 \%)$ & $6(24 \%)$ & $123(34 \%)$ & NS & NS \\
\hline \multicolumn{6}{|l|}{ Comorbidities } \\
\hline Overall comorbidity & $53(62 \%)$ & $15(60 \%)$ & $163(46 \%)$ & NS & $<.05$ \\
\hline Cardiac disease & $15(18 \%)$ & $5(20 \%)$ & $27(8 \%)$ & NS & $<.01$ \\
\hline Hypertension & $33(39 \%)$ & $9(36 \%)$ & $81(23 \%)$ & NS & $<.01$ \\
\hline Diabetes Mellitus & $10(12 \%)$ & $3(12 \%)$ & $52(15 \%)$ & NS & NS \\
\hline Respiratory disease & $7(8 \%)$ & $3(12 \%)$ & $14(4 \%)$ & NS & NS \\
\hline Renal disease & $6(7 \%)$ & $1(1 \%)$ & $10(3 \%)$ & NS & NS \\
\hline Cerebrovascular disease & $5(6 \%)$ & $1(1 \%)$ & $5(1 \%)$ & NS & $<.05$ \\
\hline Preoperative chemotherapy & $2(2 \%)$ & $1(1 \%)$ & $18(5 \%)$ & NS & NS \\
\hline Postoperative chemotherapy & 8 (9\%) & $4(16 \%)$ & $127(35 \%)$ & NS & $<.01$ \\
\hline
\end{tabular}

ASA-PS American Society of Anesthesiologists physical status, LAC-E laparoscopic surgery in elderly patients, LAC-NE laparoscopic surgery in non-elderly patients, NS not significant, OC-E open surgery in elderly patients

LAC-NE group had higher percentage of men and postoperative chemotherapy than the LAC-E group. And, ASA-PS, presence of symptom, and overall comorbidity were significantly higher in the LAC-E group than that in the LAC-NE group.

Comparisons between the LAC-E and OC-E groups are summarized in Table 2. Pathological findings including $\mathrm{pT}$ stage and $\mathrm{pN}$ stage were not statistically different between the two groups. Regarding the short-term outcomes, the amount of blood loss (LAC-E vs. OC-E: 97 vs. $440 \mathrm{~g}, p<.01)$ and the rate of morbidity ( $\geq \mathrm{CD}$ grade II) $(14 \%$ vs. $32 \%, p<.05)$ in the LAC-E group were significantly lower than those in the OC-E group. In the analysis of long-term outcomes, there were no significant differences in 5-year OS (LAC-E vs. OC-E: $63.5 \%$ vs. $52 \%$ ) (Fig. 1a) and 5 -year DSS ( $82.4 \%$ vs. $72 \%$ ) (Fig. 1b) between the two groups.

Comparisons between the LAC-E and LAC-NE groups are summarized in Table 3. The proportions of patients who had pathological tumor stage T0-1 were significantly higher in the LAC-NE group than LAC-E group (LAC-NE vs. LAC-E: $26.2 \%$ vs. $15.2 \%, p<.05)$. Among the short-term outcomes, operation time was shorter in the LAC-E group than LAC-NE group (249 vs. $288 \mathrm{~min}$, $p<.01)$. There were no differences in blood loss, the incidence of postoperative complications, days to solid diet, and length of hospital stay between the two groups. In the long-term outcomes, the 5-year OS rate in the LAC-E group was significantly lower than that in the LAC-NE group $(63.5 \%$ vs. $79.6 \%, p<.01)$ (Fig. 2a), whereas there was no significant difference between the two groups in 5-year DSS (82.4\% vs. 76\%) (Fig. 2b).

\section{Discussion}

In the present study, to clarify the technical and oncological safety of laparoscopic surgery for colorectal cancer in the elderly, we compared the short- and long-term outcomes between the elderly patients in the laparoscopic surgery and open surgery groups, and the non-elderly patients in the laparoscopic surgery group. The results of the comparison between the laparoscopic surgery and open surgery groups of elderly patients showed that the intraoperative blood loss and incidence of postoperative complications were significantly lower in the laparoscopic group, and there were no differences in long-term outcomes between the two groups. When comparing the elderly and non-elderly laparoscopic surgery groups, the operation time was significantly shorter in the elderly group. In terms of long-term outcomes, although the elderly group had shorter OS, there was no difference in DSS between the two groups. These results suggest that laparoscopic colorectal surgery is less invasive than open surgery 
Table 2 Pathological findings and short-term outcomes in the LAC-E and OC-E groups

\begin{tabular}{|c|c|c|c|}
\hline Factors & $\begin{array}{l}\text { LAC-E group } \\
(n=85)\end{array}$ & $\begin{array}{l}\text { OC-E group } \\
(n=25)\end{array}$ & $P$-value \\
\hline \multicolumn{4}{|l|}{ Pathological findings } \\
\hline \multicolumn{4}{|l|}{ Tumor location } \\
\hline Right colon & $38(44 \%)$ & $9(36 \%)$ & \multirow[t]{3}{*}{ NS } \\
\hline Left colon & $15(18 \%)$ & $6(24 \%)$ & \\
\hline Rectum & $32(38 \%)$ & $10(40 \%)$ & \\
\hline \multicolumn{4}{|l|}{ Tumor differentiation } \\
\hline Well/moderately & $75(88 \%)$ & $21(84 \%)$ & \multirow[t]{2}{*}{ NS } \\
\hline Poorly/mucinous & $10(12 \%)$ & $4(16 \%)$ & \\
\hline Tumor size $(\mathrm{mm}$, mean $\pm \mathrm{SD})$ & $47 \pm 21$ & $67 \pm 29$ & NS \\
\hline \multicolumn{4}{|l|}{ pT stage } \\
\hline $\mathrm{T0}-\mathrm{T} 1$ & $13(15 \%)$ & $1(4 \%)$ & \multirow[t]{2}{*}{ NS } \\
\hline $\mathrm{T} 2-\mathrm{T} 4$ & $72(85 \%)$ & $24(96 \%)$ & \\
\hline \multicolumn{4}{|l|}{ pN stage } \\
\hline No & $50(59 \%)$ & $16(64 \%)$ & \multirow[t]{2}{*}{ NS } \\
\hline $\mathrm{N} 1-\mathrm{N} 2$ & $35(41 \%)$ & $9(36 \%)$ & \\
\hline \multicolumn{4}{|l|}{ TNM Stage } \\
\hline $0-11$ & 47 (55\%) & $16(64 \%)$ & \multirow[t]{2}{*}{ NS } \\
\hline III-IV & $38(45 \%)$ & $9(36 \%)$ & \\
\hline \multicolumn{4}{|l|}{ Short-term outcomes } \\
\hline Operative time (min, mean \pm SD) & $249 \pm 87$ & $223 \pm 111$ & NS \\
\hline Blood loss ( $g$, mean $\pm S D$ ) & $97 \pm 124$ & $440 \pm 740$ & $<.01$ \\
\hline Intraoperative complication & 0 & 0 & NS \\
\hline Days to solid diet (days, mean $\pm S D$ ) & $4.1 \pm 2$ & $4.6 \pm 2$ & NS \\
\hline Length of hospital stay (days, mean \pm SD) & $23 \pm 39$ & $35 \pm 37$ & NS \\
\hline \multicolumn{4}{|l|}{ Postoperative complication } \\
\hline Mortality & 0 & 0 & NS \\
\hline Overall morbidity (CD grade 2 or more) & $12(14 \%)$ & $8(32 \%)$ & $<.05$ \\
\hline Anastomotic leakage & 0 & 0 & NS \\
\hline Bowel obstruction & $5(6 \%)$ & $3(12 \%)$ & NS \\
\hline Enterocolitis & $3(4 \%)$ & $1(4 \%)$ & NS \\
\hline Intraabdominal abscess & $2(2 \%)$ & $1(4 \%)$ & NS \\
\hline Bleeding & 0 & 0 & NS \\
\hline Pneumonia & 0 & $1(4 \%)$ & NS \\
\hline Others & $2(2 \%)$ & $2(8 \%)$ & NS \\
\hline
\end{tabular}

CD Clavien-Dindo, LAC-E laparoscopic surgery in elderly patients, NS not significant, OC-E open surgery in elderly patients

and is oncologically safe for elderly patients and for younger patients.

As shown in previous reports, laparoscopic colorectal surgery for elderly patients had advantages in short-term outcomes such as intraoperative blood loss, time to normal bowel function, and the length of hospital stay, similar to those in younger patients $[15,16]$. However, our results showed that there was no advantage related to length of hospital stay in the laparoscopic group. This finding might have been caused by the lack of a clinical pathway system in our department. Because there was no clinical pathway system into our department, we might not have recommended that elderly patients be discharged from hospital, despite the early recovery of the patients in the laparoscopic group. The fact that there was also no difference in the postoperative course between the elderly and non-elderly patients in our study supports our view. 

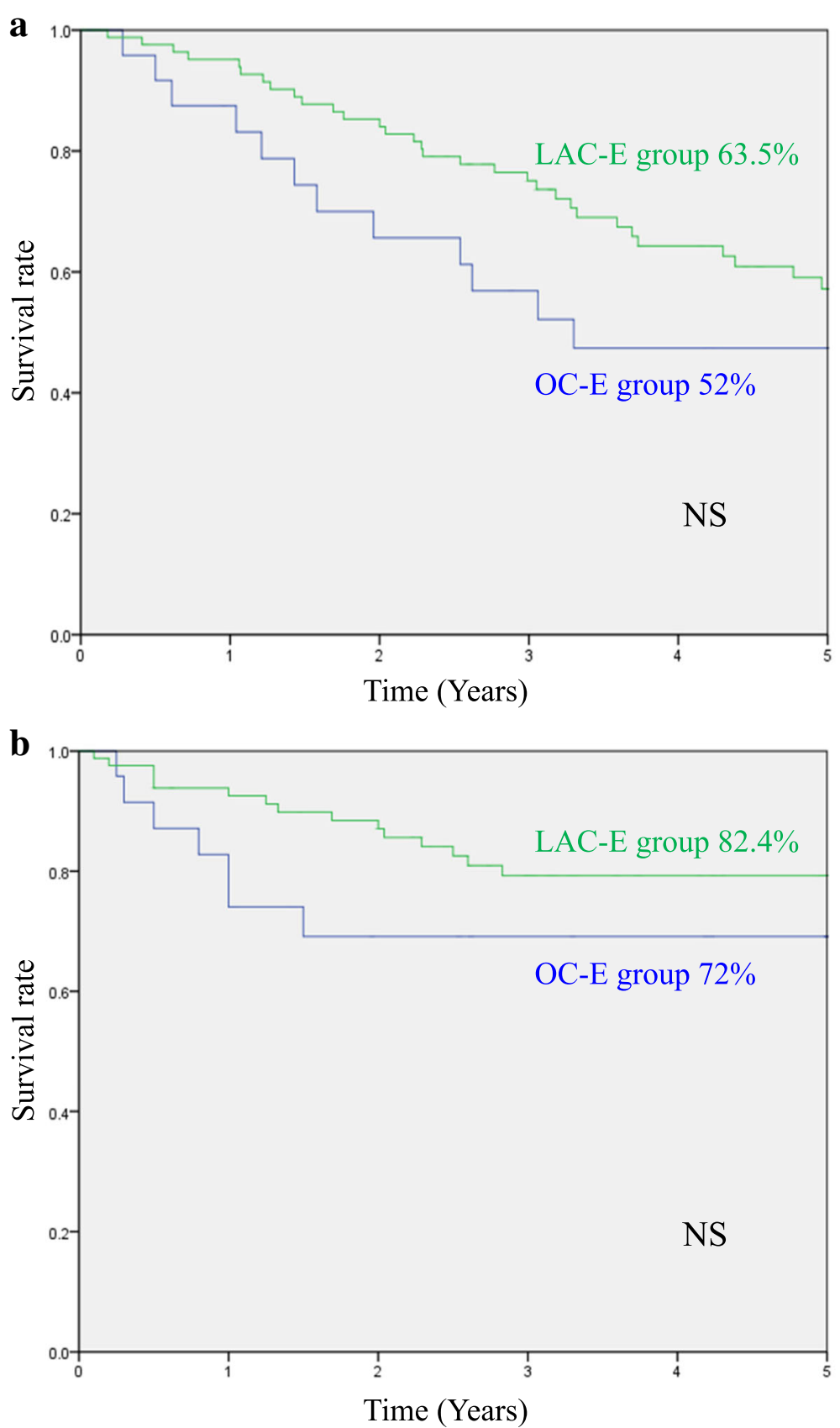

Fig. 1 a Comparison of 5-year overall survival between LAC-E and OC-E groups. b Comparison of 5-year disease-specific survival between LAC-E and OC-E groups

In this study, the average operation time was about 30 min shorter in the elderly laparoscopic group than nonelderly group. The reason was considered the possibility in which the operation team tried to shorten the operation time as much as possible because of higher ASA-PS and many comorbidities in the elderly laparoscopic group. So far, the operation time has been identified as a risk factor associated with the occurrence of postoperative complications of laparoscopic colectomy. Bailey et al. revealed that the operation time $>3 \mathrm{~h}$ was an independent risk factor for infectious complications in patients undergoing a laparoscopic right colectomy [17]. Scheer et al. also reported that colectomies lasting more than 270 min were associated with increased postoperative complications, extension of days to surgical diet, and longer hospital stay [18]. In our study including rectal cancer, it is not clear how shortening the operation time contributed to the incidence of complications and early postoperative recovery 
Table 3 Pathological findings and short-term outcomes in the LAC-E and LAC-NE groups

\begin{tabular}{|c|c|c|c|}
\hline Factors & $\begin{array}{l}\text { LAC-E group } \\
(n=85)\end{array}$ & $\begin{array}{l}\text { LAC-NE group } \\
(n=358)\end{array}$ & $P$-value \\
\hline \multicolumn{4}{|l|}{ Pathological findings } \\
\hline \multicolumn{4}{|l|}{ Tumor location } \\
\hline Right colon & $38(44 \%)$ & $116(32 \%)$ & \multirow[t]{3}{*}{ NS } \\
\hline Left colon & $15(18 \%)$ & $92(26 \%)$ & \\
\hline Rectum & $32(38 \%)$ & $150(42 \%)$ & \\
\hline \multicolumn{4}{|l|}{ Tumor differentiation } \\
\hline Well/moderately & $75(88 \%)$ & 325 (91\%) & \multirow[t]{2}{*}{ NS } \\
\hline Poorly/mucinous & $10(12 \%)$ & $33(9 \%)$ & \\
\hline Tumor size $(\mathrm{mm}$, mean $\pm \mathrm{SD})$ & $47 \pm 21$ & $41 \pm 20$ & NS \\
\hline \multicolumn{4}{|l|}{ pT stage } \\
\hline $\mathrm{T0}-\mathrm{T} 1$ & $13(15 \%)$ & $94(26 \%)$ & \multirow[t]{2}{*}{$<.05$} \\
\hline $\mathrm{T} 2-\mathrm{T} 4$ & $72(85 \%)$ & $264(74 \%)$ & \\
\hline \multicolumn{4}{|l|}{ pN stage } \\
\hline No & $50(59 \%)$ & $233(65 \%)$ & \multirow[t]{2}{*}{ NS } \\
\hline $\mathrm{N} 1-\mathrm{N} 2$ & $35(41 \%)$ & 125 (35\%) & \\
\hline \multicolumn{4}{|l|}{ TNM Stage } \\
\hline $0-\|$ & $47(55 \%)$ & $226(63 \%)$ & \multirow[t]{2}{*}{ NS } \\
\hline III-IV & $38(45 \%)$ & $132(37 \%)$ & \\
\hline \multicolumn{4}{|l|}{ Short-term outcomes } \\
\hline Operative time (min, mean \pm SD) & $249 \pm 87$ & $288 \pm 118$ & $<.01$ \\
\hline Blood loss ( $g$, mean $\pm S D$ ) & $97 \pm 124$ & $125 \pm 223$ & NS \\
\hline Intraoperative complication & 0 & 1 & NS \\
\hline Conversion to open surgery & 0 & 1 & NS \\
\hline Days to solid diet (days, mean \pm SD) & $4.1 \pm 2$ & $4.5 \pm 4$ & NS \\
\hline Length of hospital stay (days, mean \pm SD) & $23 \pm 39$ & $18.2 \pm 16$ & NS \\
\hline \multicolumn{4}{|l|}{ Postoperative complication } \\
\hline Mortality & 0 & 0 & NS \\
\hline Overall morbidity (CD grade 2 or more) & $12(14 \%)$ & $32(9 \%)$ & NS \\
\hline Anastomotic leakage & 0 & $4(1 \%)$ & NS \\
\hline Bowel obstruction & $5(6 \%)$ & $9(3 \%)$ & NS \\
\hline Enterocolitis & $3(4 \%)$ & $7(2 \%)$ & NS \\
\hline Intraabdominal abscess & $2(2 \%)$ & $6(2 \%)$ & NS \\
\hline Bleeding & 0 & $2(0.6 \%)$ & NS \\
\hline Pneumonia & 0 & 0 & NS \\
\hline Others & $2(2 \%)$ & $4(1 \%)$ & NS \\
\hline
\end{tabular}

$C D$ Clavien-Dindo, LAC-E laparoscopic surgery in elderly patients, NS not significant, $L A C-N E$ laparoscopic surgery in non-elderly patients

in the elderly laparoscopic group. We consider that it will be necessary to evaluate the effect of operative time on the incidence of complication, in order to improve the safety of laparoscopic surgery for elderly patients with colorectal cancer from now on.

In relation to postoperative complications, some of the previous studies in elderly patients have reported the rates of morbidity in laparoscopic and open surgery to be similar $[19,20]$. In contrast, other studies have shown that the rate of overall morbidity was lower in laparoscopic surgery than in open surgery [21-25]. Kennedy et al. reported that open surgery was one of the factors associated with an increased risk of complications in multivariate analysis using the database of the American College of Surgeons for elderly patients with colon cancer [26]. We also observed a lower rate of overall 

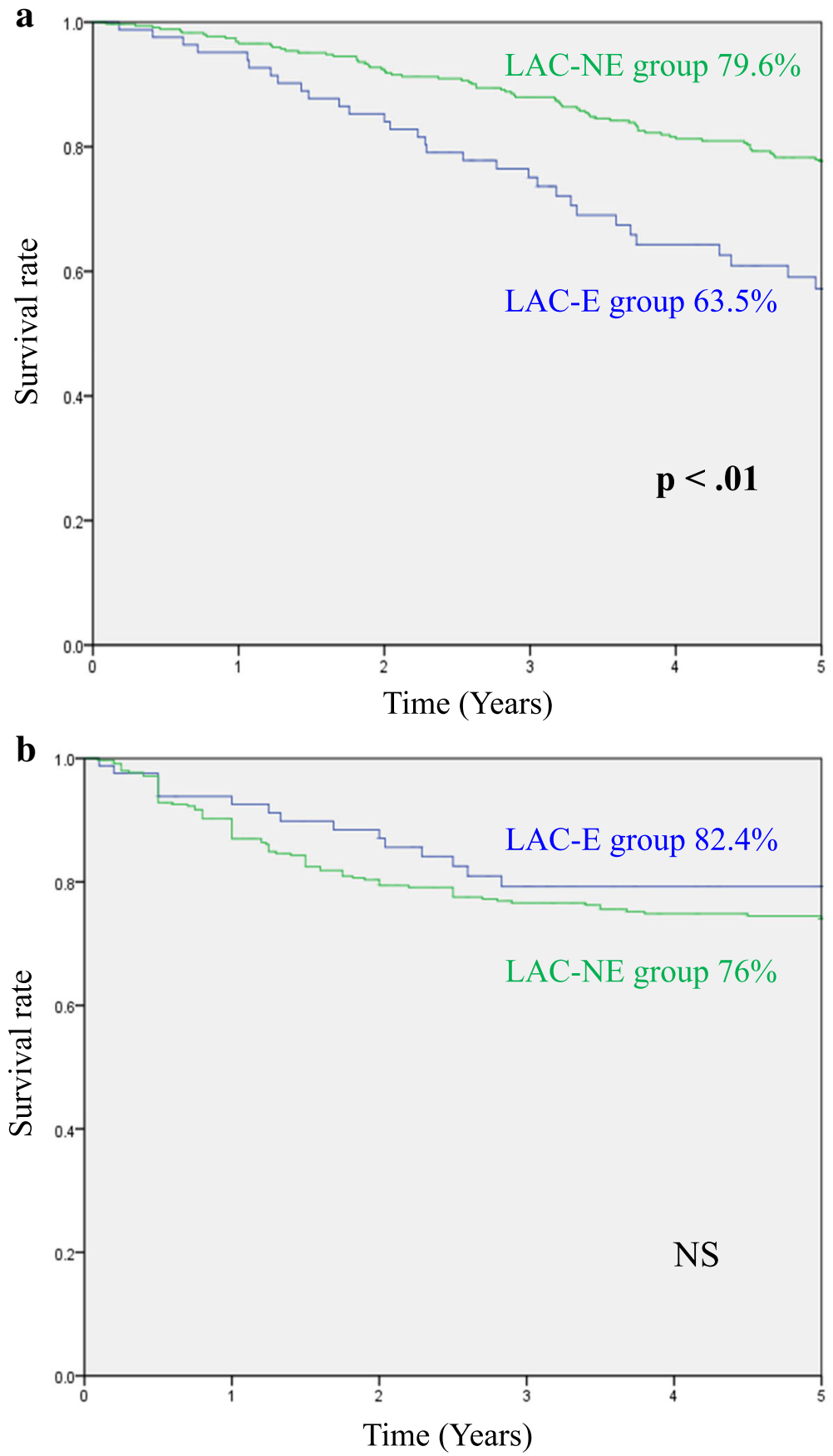

Fig. 2 a Comparison of 5-year overall survival between LAC-E and LAC-NE groups. $\mathbf{b}$ Comparison of 5-year disease-specific survival between LAC$\mathrm{E}$ and LAC-NE groups

morbidity in the laparoscopic group than that in the open group. However, it is still controversial whether laparoscopic colorectal surgery for elderly patients is as safe as it is in non-elderly patients. It is general knowledge that the incidence of postoperative complications causing a serious condition after major digestive surgery is considered to be higher in elderly patients because of the reduced functional potential of their organs and having significant age-related comorbidities such as cardiovascular and pulmonary disease [27-29]. Hermans et al. also reported that the incidence of complications in elderly patients was significantly higher than that in younger patients [30]. However, Tokuhara et al. reported in a prospective cohort study that there were no differences between the elderly and younger patients in the incidence of postoperative complications after laparoscopic 
colorectal surgery [31]. Kahn et al. found that older age is not independently associated with complications after surgery for colorectal cancer [32]. Our results also showed that the rate of postoperative complications in the elderly patients did not increase compared with that in the nonelderly patients, in spite of the higher status of ASA-PS and the greater number of comorbidities in the elderly patients. These results suggest that laparoscopic colorectal surgery is as equally safe for elderly patients as it is for younger patients.

Regarding the long-term outcomes in this study, no significant differences in OS and DSS were shown between the laparoscopic and open group of elderly patients. These results were consistent with previous randomized control trials in non-elderly patients between laparoscopic and open surgery [33-35]. Niitsu et al. also reported that laparoscopic surgery for elderly colorectal cancer patients with poor PS was not inferior to open surgery in terms of survival [21]. We also believe that laparoscopic surgery for colorectal cancer has equivalent oncological safety to that of open surgery among elderly patients. However, there have been only a few reports comparing long-term outcomes of laparoscopic colorectal surgery between elderly and nonelderly patients. Tokuhara et al. reported that there were no differences in recurrence-free survival and OS between elderly ( $\geq 75$ years) and non-elderly ( $<75$ years) patients in a prospective cohort study [31]. Jeong et al. reported that there was no difference between two groups in 3-year disease-free survival, although 3-year OS in the group aged $\geq 75$ years was lower than that of the younger group [36]. The present study also found that only OS in the elderly patients was lower than that in the non-elderly patients. The main reason is that elderly patients die because of diseases other than colorectal cancer. We did not find any significant differences in DSS between the elderly and non-elderly patients, so we believe that laparoscopic colorectal surgery for elderly patients is not inferior to that for non-elderly patients in terms of oncological safety.

There are some limitations in this study. First, this was a single-center, retrospective study. Second, there was selection bias in regard to the choice of the operation method in our study because it differed depending on the time period. Laparoscopic colorectal surgery for elderly patients was indicated in $50 \%$ of patients in 2007, whereas this ratio increased to $78 \%$ in 2014 in the present study. Lastly, differences in patient characteristics between the elderly and non-elderly patients, such as in TNM stage and perioperative chemotherapy, may also be a problem. It was difficult to apply the casematching study due to insufficient sample size in this study. In the future, a large-scale multicenter prospective randomized controlled study is necessary.

\section{Conclusions}

In conclusion, laparoscopic colorectal surgery for elderly patients aged $\geq 80$ years was less invasive and technically safer than open surgery and provided a surgical cure as it did for non-elderly patients. From the results of our study, we consider laparoscopic colorectal surgery to be an optimal procedure for elderly patients with colorectal cancer. To confirm our opinion, a multi-center prospective study with larger sample size would be required in the near future. The number of elderly patients with colorectal cancer will continue to increase. It is also necessary to establish the treatment guideline including postoperative care and palliative surgery for elderly patients with colorectal cancer.

\section{Abbreviations}

ASA-PS: American Society of Anesthesiologists physical status; CD: ClavienDindo classification; OS: Overall survival; DSS: Disease-specific survival

\section{Acknowledgements}

Not applicable.

\section{Authors' contributions}

Study concept: YU and NS. Study design: YU, NS and MI. Data acquisition: YU, TK, TA, SN, HS and TE. Data analysis and interpretation: YU, TA, HS and TE. Manuscript preparation: YU and NS. Manuscript editing: YU and TE. Manuscript review: NS and MI. All the authors have read and approved the final version of the manuscript.

\section{Funding}

This research did not receive any specific grant from funding agencies in the public, commercial, or not-for-profit sectors.

\section{Availability of data and materials}

All data generated or analysed during this study are included in this published article.

\section{Ethics approval and consent to participate}

This study was approved by the Ethical Committee of Oita University Faculty of Medicine, and all patients included in the study gave their written informed consent.

Consent for publication

Not applicable.

\section{Competing interests}

The authors declare that they have no competing interests.

\section{Author details}

${ }^{1}$ Department of Comprehensive Surgery for Community Medicine, Oita University Faculty of Medicine, Hasama-machi, Oita 879-5593, Japan. ${ }^{2}$ Department of Gastroenterological and Pediatric Surgery, Oita University Faculty of Medicine, Oita, Japan.

Received: 18 June 2020 Accepted: 17 September 2020

Published online: 04 November 2020

\section{References}

1. Bray F, Ferlay J, Soerjomataram I, Siegel RL, Torre LA, Jemal A. Global Cancer statistics 2018: GLOBOCAN estimates of incidence and mortality worldwide for 36 cancers in 185 countries. CA Cancer J Clin. 2018;68:394-424.

2. Center for Cancer Control and Information Services. Cancer Statistics in Japan. National Cancer Center, Japan. Available at: https://ganjoho.jp/reg_ stat/statistics/stat/summary.html. Accessed 10 March 2020. In Japanese.

3. Rasool S, Kadla SA, Rasool V, Ganai BA. A comparative overview of general risk factors associated with the incidence of colorectal cancer. Tumour Biol. 2013;34:2469-76. 
4. Cancer Registry and Statistics. (Monitoring of Cancer Incidence in Japan $(\mathrm{MCIJ})$ ). Cancer Information Service, National Cancer Center, Japan. Available at: https://ganjoho.jp/reg_stat/statistics/dl/index.html. Accessed 10 March 2020. In Japanese.

5. Athanasiou CD, Robinson J, Yiasemidou M, Lockwood S, Markides GA. Laparoscopic vs open approach for transverse colon cancer. A systematic review and metaanalysis of short and long term outcomes. Int J Surg. 2017; 41:78-85.

6. Parker JM, Feldmann TF, Cologne KG. Advances in laparoscopic colorectal surgery. Surg Clin North Am. 2017;97:547-60.

7. Reza MM, Blasco JA, Andradas E, Cantero R, Mayol J. Systematic review of laparoscopic versus open surgery for colorectal cancer. Br J Surg. 2006;93:9218.

8. Fleshman J, Sargent DJ, Green E, Anvari M, Stryker SJ, Beart RW Jr, Hellinger M, Flanagan R Jr, Peters W, Nelson H. Clinical Outcomes of Surgical Therapy Study Group. Laparoscopic colectomy for cancer is not inferior to open surgery based on 5-year data from COST Study Group trial. Ann Surg. 2007; 246:655-62.

9. Lacy AM, Delgado S, Castells A, Prins HA, Arroyo V, Ibarzabal A, Pique JM. The long-term results of a randomized clinical trial of laparoscopy-assisted versus open surgery for colon cancer. Ann Surg. 2008;248:1-7.

10. Colon Cancer Laparoscopic or Open Resection Study Group, Buunen M, Veldkamp R, Hop WC, Kuhry E, Jeekel J, Haglind E, Påhlman L, Cuesta MA, Msika S, Morino M, Lacy A, Bonjer HJ. Survival after laparoscopic surgery versus open surgery for colon cancer: long-term outcome of randomized clinical trial. Lancet Oncol. 2009;10:44-52.

11. Jayne DG, Thorpe HC, Copeland J, Quirke P, Brown JM, Guillou PJ. Five-year follow-up of the Medical Research Council CLASICC trial of laparoscopically assisted versus open surgery for colorectal cancer. Br J Surg. 2010;97:1638-45.

12. Inomata $M$, Shiroshita $H$, Uchida $H$, Bandoh $T$, Akira $S$, Yamaguchi $S$, Kurokawa Y, Seki Y, Eguchi S, Wada N, Takiguchi S, leiri S, Endo S, Iwazaki M, Sato Y, Tamaki Y, Kitamura K, Tabata M, Kanayama H, Mimata H, Hasegawa T, Takahashi H, Onishi K, Uemura T, Hashizume M, Matsumoto S, Kitano S, Watanabe M. Current status of endoscopic surgery in Japan: the 14th National Survey of endoscopic surgery by the Japan Society for Endoscopic Surgery. Asian J Endosc Surg. 2020;13:7-18.

13. Leslie HS, Mary KG, Christian W. The TNM classification of malignant tumors. 7th ed. Hoboken: Wiley-Blackwell; 2009.

14. Clavien PA, Barkun J, de Oliveira ML, Vauthey JN, Dindo D, Schulick RD, de Santibañes E, Pekolj J, Slankamenac K, Bassi C, Graf R, Vonlanthen R, Padbury $\mathrm{R}$, Cameron JL, Makuuchi M. The Clavien-Dindo classification of surgical complications: five-year experience. Ann Surg. 2010;250:187-96.

15. Grailey K, Markar SR, Karthikesalingam A, Aboud R, Ziprin P, Faiz O. Laparoscopic versus open colorectal resection in the elderly population. Surg Endosc. 2013;27:19-30.

16. Antoniou SA, Antoniou GA, Koch OO, Pointner R, Granderath FA. Laparoscopic colorectal surgery confers lower mortality in the elderly: a systematic review and meta-analysis of 66,483 patients. Surg Endosc. 2015; 29:322-33.

17. Bailey MB, Davenport DL, Vargas HD, Evers BM, McKenzie SP. Longer operative time: deterioration of clinical outcomes of laparoscopic colectomy versus open colectomy. Dis Colon Rectum. 2014;57:616-22.

18. Scheer A, Martel G, Moloo H, Sabri E, Poulin EC, Mamazza J, Boushey RP. Laparoscopic colon surgery: does operative time matter? Dis Colon Rectum. 2009:52:1746-52.

19. Nishikawa T, Ishihara S, Hata K, Murono K, Yasuda K, Otani K, Tanaka T, Kiyomatsu T, Kawai K, Nozawa H, Yamaguchi H, Watanabe T. Short-term outcomes of open versus laparoscopic surgery in elderly patients with colorectal cancer. Surg Endosc. 2016;30:5550-7.

20. Devoto L, Celentano V, Cohen R, Khan J, Chand M. Colorectal cancer surgery in the very elderly patient: a systematic review of laparoscopic versus open colorectal resection. Int J Color Dis. 2017;32:1237-42.

21. Niitsu $H$, Hinoi $T$, Kawaguchi $Y$, Ohdan $H$, Hasegawa $H$, Suzuka I, Fukunaga Y, Yamaguchi T, Endo S, Tagami S, Idani H, Ichihara T, Watanabe K, Watanabe M, Japan Society of Laparoscopic Colorectal Surgery. Laparoscopic surgery for colorectal cancer is safe and has survival outcomes similar to those of open surgery in elderly patients with a poor performance status: subanalysis of a large multicenter case-control study in Japan. J Gastroenterol. 2016;51:43-54.

22. Fujii S, Tsukamoto M, Fukushima Y, Shimada R, Okamoto K, Tsuchiya T, Nozawa K, Matsuda K, Hashiguchi Y. Systematic review of laparoscopic vs open surgery for colorectal cancer in elderly patients. World J Gastrointest Oncol. 2016:8:573-82.

23. Itatani Y, Kawada K, Sakai Y. Treatment of elderly patients with colorectal cancer. Biomed Res Int. 2018;2176056. https://doi.org/10.1155/2018/ 2176056.

24. Allardyce RA, Bagshaw PF, Frampton CM, Frizelle FA, Hewett PJ, Rieger NA, Smith JS, Solomon MJ, Stevenson AR. Australasian laparoscopic Colon Cancer study shows that elderly patients may benefit from lower postoperative complication rates following laparoscopic versus open resection. Br J Surg. 2010;97:86-91.

25. Frasson M, Braga M, Vignali A, Zuliani W, Di Carlo V. Benefits of laparoscopic colorectal resection are more pronounced in elderly patients. Dis Colon Rectum. 2008:51:296-300.

26. Kennedy GD, Rajamanickam V, O'Connor ES, Loconte NK, Foley EF, Leverson $\mathrm{G}$, Heise CP. Optimizing surgical care of colon cancer in the older adult population. Ann Surg. 2011;253:508-14.

27. Turrentine FE, Wang H, Simpson VB, Jones RS. Surgical risk factors, morbidity, and mortality in elderly patients. J Am Coll Surg. 2006;203:865-77.

28. Duron JJ, Duron E, Dugue T, Pujol J, Muscari F, Collet D, Pessaux P, Hay JM. Risk factors for mortality in major digestive surgery in the elderly: a multicenter prospective study. Ann Surg. 2011;254:375-82.

29. Grosso G, Biondi A, Marventano S, Mistretta A, Calabrese G, Basile F. Major postoperative complications and survival for colon cancer elderly patients. BMC Surg. 2012;12(Suppl 1):S20.

30. Hermans E, van Schaik PM, Prins HA, Ernst MF, Dautzenberg PJ, Bosscha K. Outcome of colonic surgery in elderly patients with colon cancer. J Oncol. 2010;865908:1-5.

31. Tokuhara K, Nakatani K, Ueyama Y, Yoshioka K, Kon M. Short- and long-term outcomes of laparoscopic surgery for colorectal cancer in the elderly: a prospective cohort study. Int J Surg. 2016;27:66-71.

32. Kahn KL, Adams JL, Weeks JC, Chrischilles EA, Schrag D, Ayanian JZ, Kiefe Cl, Ganz PA, Bhoopalam N, Potosky AL, Harrington DP, Fletcher RH. Adjuvant chemotherapy use and adverse events among older patients with stage III colon cancer. JAMA. 2010;303:1037-45.

33. Clinical Outcomes of Surgical Therapy Study Group, Nelson H, Sargent DJ, Wieand HS, Fleshman J, Anvari M, Stryker SJ, Beart RW Jr, Hellinger M, Flanagan R Jr, Peters W, Ota D. A comparison laparoscopically assisted and open colectomy for colon cancer. N Engl J Med. 2004;350:2050-9.

34. Colon Cancer Laparoscopic or Open Resection Study Group, Buunen M, Veldkamp R, Hop WC, Kuhry E, Jeekel J, Haglind E, Påhlman L, Cuesta MA, Msika S, Morino M, Lacy A, Bonjer HJ. Survival after laparoscopic surgery versus open surgery for colon cancer: long-term outcome of a randomised clinical trial. Lancet Oncol. 2009;10:44-52.

35. Hemandas AK, Abdelrahman T, Flashman KG, Skull AJ, Senapati A, O'Leary DP, Parvaiz A. Laparoscopic colorectal surgery produces better outcomes for high risk cancer patients compared to open surgery. Ann Surg. 2010;252:84-9.

36. Jeong DH, Hur H, Min BS, Baik SH, Kim NK. Safety and feasibility of a laparoscopic colorectal cancer resection in elderly patients. Ann Coloproctol. 2013;29:22-7.

\section{Publisher's Note}

Springer Nature remains neutral with regard to jurisdictional claims in published maps and institutional affiliations.

Ready to submit your research? Choose BMC and benefit from:

- fast, convenient online submission

- thorough peer review by experienced researchers in your field

- rapid publication on acceptance

- support for research data, including large and complex data types

- gold Open Access which fosters wider collaboration and increased citations

- maximum visibility for your research: over $100 \mathrm{M}$ website views per year

At BMC, research is always in progress.

Learn more biomedcentral.com/submissions 